Article

\title{
A High Resolution Coupled Fire-Atmosphere Forecasting System to Minimize the Impacts of Wildland Fires: Applications to the Chimney Tops II Wildland Event
}

\author{
Pedro A. Jiménez *, Domingo Muñoz-Esparza and Branko Kosović \\ Research Applications Laboratory, National Center for Atmospheric Research, 3450 Mitchell Ln., \\ Boulder, CO 80301, USA; domingom@ucar.edu (D.M.-E.); branko@ucar.edu (B.K.) \\ * Correspondence: jimenez@ucar.edu; Tel.: +1-303-497-8201
}

Received: 11 April 2018; Accepted: 15 May 2018; Published: 19 May 2018

check for updates

\begin{abstract}
Wildland fires are responsible for large socio-economic impacts. Fires affect the environment, damage structures, threaten lives, cause health issues, and involve large suppression costs. These impacts can be mitigated via accurate fire spread forecast to inform the incident management team. We show that a fire forecast system based on a numerical weather prediction (NWP) model coupled with a wildland fire behavior model can provide this forecast. This was illustrated with the Chimney Tops II wildland fire responsible for large socio-economic impacts. The system was run at high horizontal resolution $(111 \mathrm{~m}$ ) over the region affected by the fire to provide a fine representation of the terrain and fuel heterogeneities and explicitly resolve atmospheric turbulence. Our findings suggest that one can use the high spatial resolution winds, fire spread and smoke forecast to minimize the adverse impacts of wildland fires.
\end{abstract}

Keywords: operational forecast sytem; fire modeling; numerical weather prediction; high spatial reoslution; WRF-Fire

\section{Introduction}

Wildland fires produce large socio-economic impacts. Wildland fires affect the environment, damage structures, threaten lives, cause health issues, and involve large suppression costs. Accurate predictions of the fire spread can aid decision makers in mitigating the impacts [1].

A wide rage of models exists to predict the spread of wildland fires [2-4]. The models range from physics-based models that resolve both the physics and chemistry of the fire spread, to empirical models that are based upon observational evidence to parameterize the fire behavior. The complexity of physical processes involved in the simulation ultimately determines the computational resources necessary to perform a fire simulation.

From an operational point of view, there needs to be a balance among the physics included in the model, the accuracy, and the computational cost. Current computational resources are insufficient to perform real-time simulations using physics-based models that resolve combustion processes. Additionally, the physical mechanisms governing the spread of wildland fires are not completely understood [5], and the physics models ultimately rely on parameterizations to simulate certain aspects of the fire. On the other extreme, empirical models require low computational resources and have been shown to adequately predict the rates of fire spread even outside of the limits of the training datasets [6]. In between, there is a variety of models with quite diverse assumptions. In general, increasing the realism of the fire, weather, topography and its interactions should be beneficial [7]. 
In this direction, coupled atmosphere-fire models [8-10] provide a balance between the realism of the physical processes represented, and the computational cost required to run a simulation.

Despite the potential of coupled atmosphere-fire models for fire spread forecast, this kind of models is not used in fire incident management today. The standard practice is to drive a particular fire spread model with an external meteorological forecast. This is an efficient methodology but presents certain limitations. A first limitation is that operational models are not typically run at the fine scales that drive the fire behavior. Finer wind fields could be obtained using diagnostic models based on mass-conservation [11,12]. However, this kind of models would not increase much the temporal resolution of the meteorological forecasts (approximately $1 \mathrm{~h}$ ). Higher temporal resolution is important when analyzing fire phenomena at fine atmospheric scales. Over the contiguous U.S., the finest meteorological forecasts available is the High Resolution Rapid Refresh (HRRR) model run by NOAA [13] at a grid spacing of $3 \mathrm{~km}$. Although this horizontal resolution can be considered high for certain NWP applications, it is not sufficient to capture relevant terrain features over regions of complex topography, fuel heterogeneities, or the fine atmospheric scales of motion that drive the fire evolution. In addition, using an external meteorological forecast prevents one from accounting for fire-atmosphere feedbacks that have shown relevance for particular wildland fires [2,3].

Here, we show that a coupled atmosphere-fire operational fire prediction system running at fine horizontal grid spacing $(111 \mathrm{~m})$ to explicitly resolve atmospheric turbulence and to accurately represent topography and fuel characteristics can provide meaningful real-time predictions to assist decision makers to minimize the impact of wildland fires. The coupled model is based on the Weather Research and forecasting (WRF) model [14], with a fire behavior model based on the Coupled Atmosphere-Wildland Fire Environment (CAWFE) model $[8,15]$. The coupled model referred to as WRF-Fire [10] is the basis of an operational fire prediction system that the National Center for Atmospheric Research (NCAR) is developing in collaboration with the Colorado Center of Excellence for Advanced Technology Aerial Firefighting (CoE). The Colorado fire prediction system (CO-FPS) will be the first operational system based on a coupled atmosphere-fire model. The configuration of WRF in a turbulence resolving mode is also an original characteristic of the operational system.

To illustrate how the forecasting system can be used to minimize the impact of wildland fires, we present simulations that could have been performed during the evolution of the Chimney Tops II fire. This fire was selected due to its large socio-economic impacts. The fire occurred in the Great Smoky Mountains National Park, Tennessee. It was first identified on 23 November 2016 at around 1730 LST in an abrupt region of the park. On 28 November 2016, the dry conditions and extreme winds led to a rapid intensification of the fire. The fire burned 17,140 Acres (purple solid line in Figure 1) and destroyed 2013 homes, 53 commercial structures and caused 14 fatalities. Our simulations of this fire show the value that high spatial resolution winds, fire spread and smoke forecast could bring to minimize the socio-economic impacts of wildland fires.
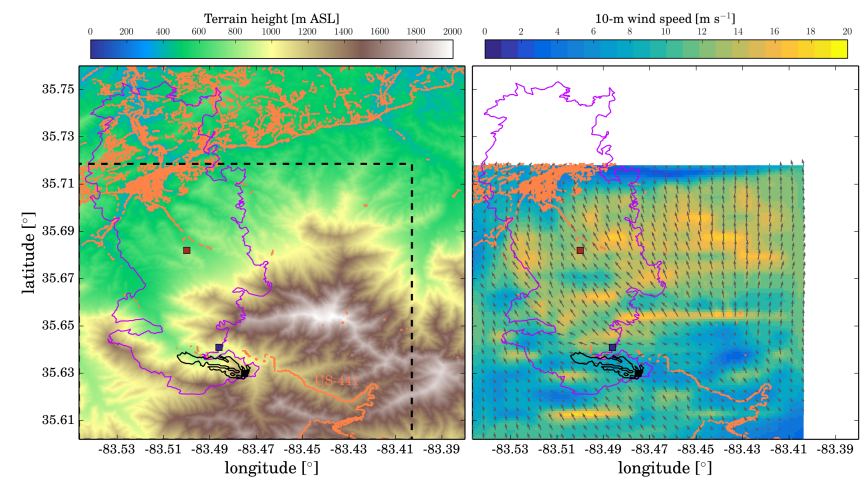

Figure 1. (Left) Elevation around the Chimney Tops II fire (shaded), region covered by the second domain in the simultaions (dashed lines), and final fire perimeter (purple line). The urban areas are highlighted in orange. (Right) Averaged near-surface wind speed calculated with the complete period simulated in SIM1. The final fire perimeter from SIM1 is also shown (black line). 


\section{Materials and Methods}

\subsection{Chimney Tops II Wildland Fire}

The incident report, briefly summarized in this section, describes the management of the fire. On 23 November 2016, when the fire was discovered, firefighters hiked to the fire. The incident commander determined that a direct fight was not safe due to thick vegetation, abrupt terrain and darkness approaching. The next day, a containment area was set up to firefight the fire in better conditions. During this day and the following two, 24-26 November, the fire grew slowly (from 1.5 burned acres to 6 acres). On 26 November, a four-day forecast was requested from the U.S. Forest Service Rocky Mountain Research Station (RMRS) (Fort Collins, CO, USA). This forecast did not predict the rapid intensification of the fire. However, the situation changed on 27 November. The weather conditions increased the fire activity and, at the end of the day, the fire had burned 35 acres. During this day, helicopters dropped bucket drops to slow down the spread of the fire. During the night, the wind speed increased. This wind event was forecasted to occur at 13 LST on 28 November but occurred during the night before, which was expected to be calm. There was no fire suppression activity during this night due to hazard conditions. On the morning of 28 November, spot fires were discovered about 1.5 mile away, outside of the containment area (blue square in Figure 1). Several hours later, at approximately 1130 LST, a new spot fire was discovered 1.5 miles away from the park boundary (red square in Figure 1), and the winds increased during the course of the day. Shortly after 1700 LST, the winds started taking down power lines which ignited some new fires in the city of Gatlinburg and part of the county. The city of Gatlinburg went from having no fires in the city at 1700 LST to having multiple active fires roughly an hour later. Around 1800 LST, evacuations started in certain areas. The fire activity continued to intensify due to the extreme wind conditions. At around 2100 LST, a message was sent to evacuate the Gatlinburg area. More than 14,000 people were evacuated. Fire activity started to subside with steady rain and diminishing winds on 29 November after 0200 LST.

\subsection{Simulations Performed with the Colorado Fire Prediction System}

To represent the fine atmospheric scales that drive the fire propagation, CO-FPS configures WRF-Fire to simulate the atmospheric evolution at $111 \mathrm{~m}$ of grid spacing. To perform this fine scale simulation, WRF-Fire downscales HRRR simulations performed by NOAA at $3 \mathrm{~km}$ horizontal grid spacing using two nested domains. The first domain has a horizontal grid spacing of $1 \mathrm{~km}$ and covers a region of $117 \mathrm{~km}$ by $117 \mathrm{~km}$. This domain provides lateral boundary conditions to the second domain that covers a region of $13.0 \mathrm{~km}$ by $13.0 \mathrm{~km}$ using the target grid spacing of $111 \mathrm{~m}$.

Several atmospheric processes are parameterized in WRF. These include both shortwave [16] and longwave [17] radiative transfer. Cloud microphysical processes are parameterized with the WRF single-moment six-class scheme [18] and land-atmosphere processes follow [19,20]. The surface layer parameterization is based on the Monin-Obukhov similarity theory [21]. The representation of turbulent mixing differs in the two domains. In Domain 1, turbulence is parameterized based on the assumption of horizontal homogeneity [22], whereas, in Domain 2, turbulence is explicitly resolved with a large-eddy simulation closure [23,24]. This improved representation of turbulence is desirable to resolve the fine atmospheric scales that drive the fire module activated in this second domain.

The fire model explicitly accounts for the effects of fire on atmospheric dynamics which, in turn, feedback to the fire behavior [10]. The process starts using the near surface winds from the atmospheric component to determine the rate of spread of the fire. The rate of spread is parameterized using Rothermel's model [25]. The fire rate of spread is used to advance the fire perimeter, tracking the interface between the burning/burned regions and the unburned fuel with the level-set method [9]. The original WRF-Fire algorithm has been improved by adding higher-order numerical schemes to solve the level-set and reinitialization equations [26]. Once a grid cell is ignited, the amount of fuel burned is calculated to provide feedback to the atmosphere via sensible and latent heat fluxes. 
The post-frontal heat release is parameterized following laboratory experiments $[27,28]$ valid for the 13 fuel-type categories of Anderson [29,30], which is the fuel classification used in WRF-Fire. To better account for fuel heterogeneities and topography, the fire grid is refined by a factor of four with respect to the atmospheric grid (i.e., $27.75 \mathrm{~m}$ ). The interested reader is referred to $[10,26]$ for a detailed description of the WRF-Fire model and the level set representation.

To illustrate the potential of an operational coupled atmosphere-fire behavior prediction system, we present simulations performed with a similar set up to what the CO-FPS will be. The first simulation (SIM1) is a three-day simulation starting on the 26 November to match the prediction requested on that day by the firefighters to the RMRS. The second and third simulations (SIM2 and SIM3) were performed to analyze fire behvior results of SIM1. Finally, two additional simulations (SPOT1 and SPOT2) were performed initializing the fire at the two fire spots identified on 28 November in the incident report (red and blue squares in Figure 1). These two simulations provide information of the fire spread during the most rapid grow of the fire.

\section{Results}

Results are divided in two sections. The first section describes the information that the simulations could have provided on 26 November (SIM1-3). The second section describes the simulations during 28 November (SPOT1 and SPOT2), the day of the rapid intensification of the fire.

\subsection{Simulations on 26 November}

The final fire perimeter from SIM1 valid at 29 November 1400 LST did not predict the rapid intensification of the fire (black line in Figure 1). This is similar to the forecast performed by RMRS that day to evaluate the potential danger of the fire.

However, the simulation provides information which should have raised concerns about the potential risk of the fire. While the wind speed near the fire front and therefore fire spread were moderate, the mean wind speed was very high in the northern side of the fire perimeter (e.g., right panel in Figure 1). This region was to the north of the US-441 road and outside of the containment area. If for some reason the fire would reach this region, the winds with prevailing northwestern direction would rapidly spread the fire towards the city of Gatlinburg. These inaccuracies could be due to limitations of a fire simulation model or to long-range spotting, which is neglected by the WRF-Fire model and was responsible for the ignition of at least one fire on the other side of the road (blue square in Figure 1).

This potential fire hazard is further illustrated with the time series of the 10-m mean wind (upper panel in Figure 2). The mean wind speed over the simulated domain indicates that the intensification of the winds started on the afternoon of 27 November, reaching significant winds during the night, and picking up to $16 \mathrm{~m} / \mathrm{s}$ on 28 November at 1800 LST. This intensification is in agreement with the timing from the incident report. The mean wind direction indicates that the fire would propagate towards Gatlinburg. The simulated increase in temperatures and reduction in relative humidity (lower panel in Figure 2) aggravated the fire hazard on 28 November.

The previous analysis motivates a quantification of the fire impacts if, for some reason, the fire crosses the road and enters the region of high winds. The impact can be quantified by igniting new fires on the other side of the road. The points can be randomly selected on the basis of the mean wind speed and the fire perimeter (right panel in Figure 1). However, in the absence of a spotting model, a viable approach is to decide the ignition points based on instantaneous winds and smoke plume dispersion. This would account for potential spot fires which is what actually happened.

Analysis of the vertically integrated smoke concentration and the winds from SIM1 at different times were used to select two point ignitions (Figure 3). First, we identified the ignition time. For this purpose, we selected the time wherein the smoke plume shows its widest extent: 28 November at 0600 LST (left panel in Figure 3). Second, we selected the ignition points. The ignition points were selected within the region covered by the significant concentration smoke plume which is the most likely region for spot fires. Additionally, the wind fields were analyzed to select relevant locations. 
Based on this analysis, we selected two locations that showed high winds at 1200 LST (right panel in Figure 3). These two fire simulations (SIM2 and SIM3) were ignited at 0600 LST when the smoke plume showed its widest extent (left panel in Figure 3).

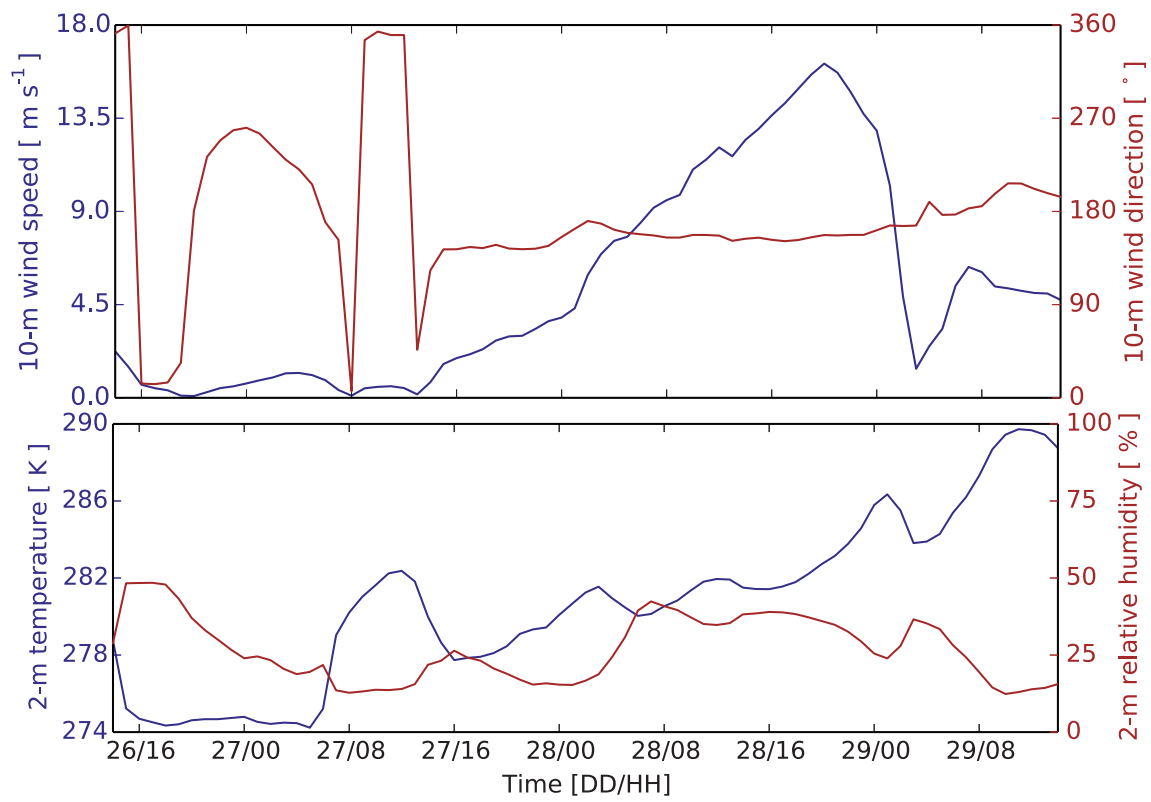

Figure 2. Time series of the Wind speed (blue) and wind direction (red) averaged over the whole simulated domain for SIM1 (upper panel). The regional $2 \mathrm{~m}$ temperature (blue) and $2 \mathrm{~m}$ relative humidity (red) time series are also shown (lower panel).

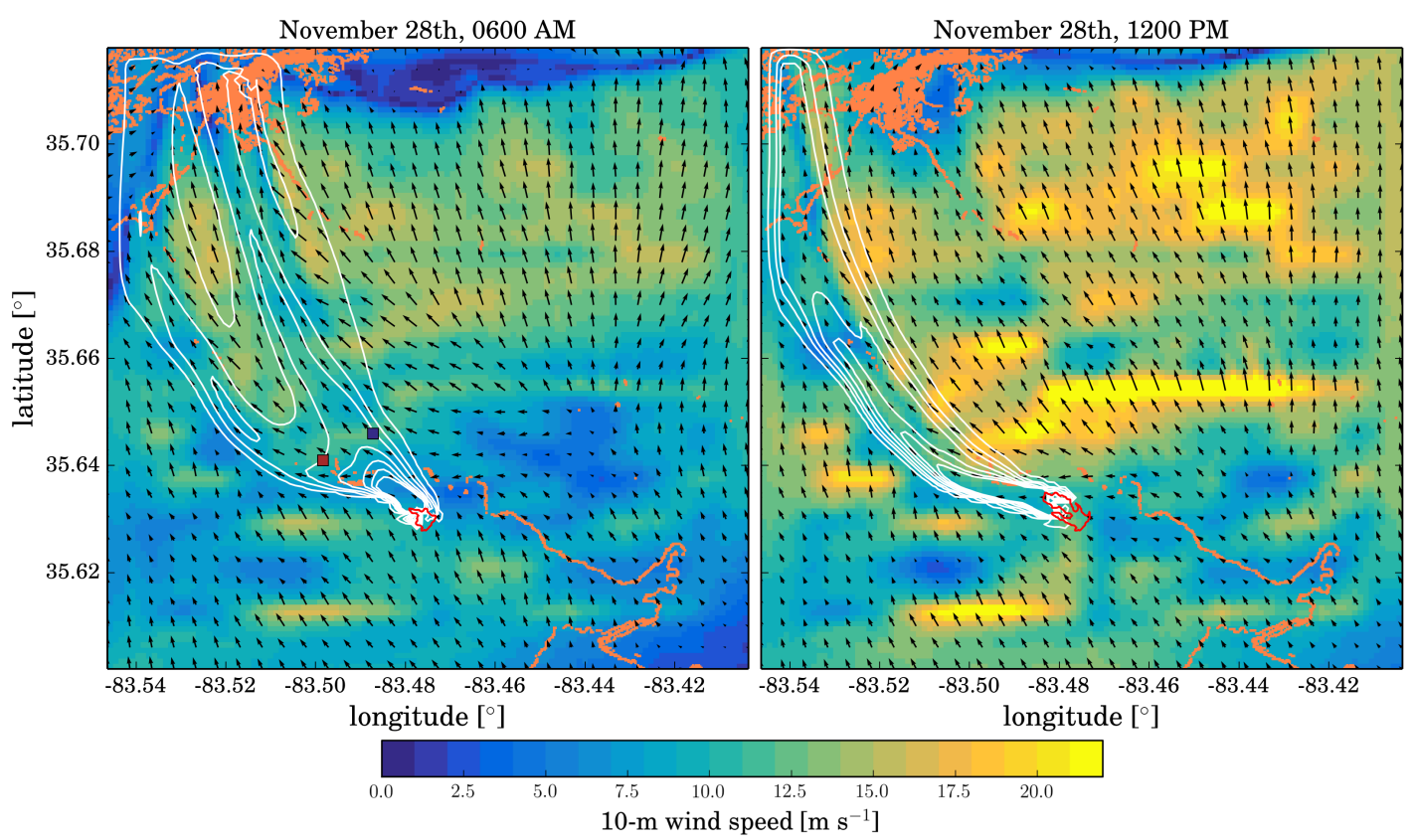

Figure 3. Smoke concentrations (white contour lines) from SIM1 at (left) 0600 LST and (right) 1200 LST on 28 November. The winds (arrows) and the wind speed (shaded) are also shown. Orange colors represent no fuel categories such as the city of Gatlinburg in the northwest of the domain and US-441 road in the southeast. 
As expected, the final fire perimeters of SIM2 and SIM3 valid for 29 November at 1400 LST reveal a larger burned area than SIM1 (left panel in Figure 4). The fire ignited in the slope of the mountain (blue square) shows a faster fire spread and it is more directed towards the city of Gatlinburg than the fire ignited closer to the valley (red square). Hence, these new simulations confirm the high fire hazard that could have been expected on 28 November if the fire crossed the US-441 road.

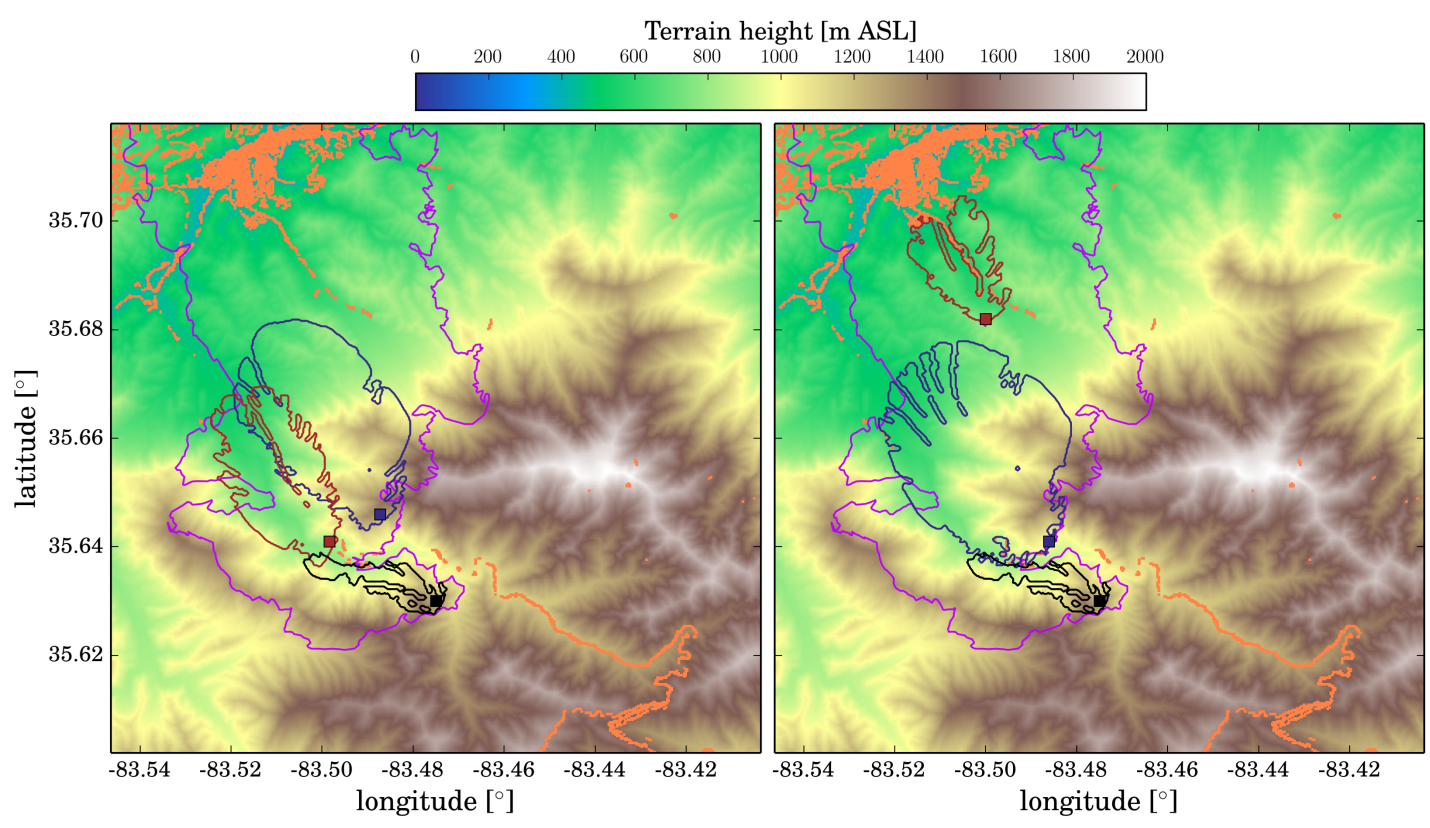

Figure 4. Fire perimeters (contour lines): at the end of the SPOT1 and SPOT2 simulations (left); and at the end of SIM2 and SIM3 (right). Elevation is also shown (shaded).

\subsection{Simulations on 28 November}

On the morning of 28 November, the first spot fire was identified (blue square in Figure 1). This spot fire was in the region with high winds identified in SIM1. If the impacts of fires ignited over this region with high winds would have been evaluated, SIM2 and SIM3, fire behavior analysis would have raised immediate concerns of the danger of the fire situation.

A new fire simulation could have been performed with the correct time and location of the spot fire right after its detection. The SPOT1 simulation mimics the ignition of this fire on the morning of 28 November. The fire perimeter valid for 29 November at 1400 LST clearly shows the rapid intensification of the spot fire (right panel in Figure 4). Such fire behavior analysis could have provided important information for decision makers to raise warnings about possible expected hazardous conditions with more confidence.

The identification of a second spot on 28 November at 1100 LST even closer to the city of Gatlinburg, based on such an analysis, would have increased the concerns of the fire situation. Based on the previous simulations (SIM1, SIM2 and SPOT1), this could have been an early warning of the potential danger for Gatlinburg citizens. A new simulation replicating the second spot fire (SPOT2) could then be launched after the identification of this new spot fire. The fire perimeter valid for 29 November at 1400 LST indicates that this fire would reach the city of Gatlinburg (right panel in Figure 4).

Figure 4 (right panel) shows the observed and simulated (SIM1, SPOT1, and SPOT2) fire perimeters valid for 29 November at 1400 LST. The combination of the simulated fire perimeters is within the observed burned region but of smaller dimension. However, the simulations only consider SPOT1 and SPOT2 and there were probably other spot fires that could have been simulated in real time. Actually, the fact that spotting was happening during the day would have been an indication 
that the real fire perimeters would have covered a larger region than the simulated ones. The fires originated by the downfall of power lines are not accounted for in the simulation and would have enlarged the burned area as well.

\section{Discussion}

The potential of a high resolution prediction system based on a coupled fire-atmosphere model, WRF-Fire, to aid in the analysis of fire behavior in the case of a high impact fire, such as Chimney Tops II, was examined. The high spatial resolution, $111 \mathrm{~m}$, implies resolving atmospheric turbulence and a more accurate representation of topography and fuels. This has been shown critical for this particular case study, wherein it has been illustrated how the high resolution wind fields and smoke can provide guidance on the potential evolution of the fire. Accounting for long-range spotting has been shown to be important, and we are exploring the implementation of appropriate spotting models in WRF-Fire to reduce human intervention in the fire forecast process. Although literature on the topic is extensive [31-38], it is still a challenge to realistically incorporate spotting phenomena in the models, while preserving computational efficiency required for operational purposes. The adequacy of spotting implementations needs to be systematically evaluated on wildland fires events where long-range spotting played a primary role in the fire spread, a good example of which is the Chimney Tops II fire.

Operational fire spread forecasting systems do not currently couple the fire model to the atmosphere and thus rely on a previously existing weather forecast. The numerical weather prediction forecasts are typically run at $10 \mathrm{~km}$ for global models and around $1 \mathrm{~km}$ for regional models. For example, the highest resolution of an operational forecast over the Contiguous U.S. is the 3 $\mathrm{km}$ grid of the HRRR model. This resolution, although can be considered high, is insufficient to represent the winds and topography around complex terrain regions such as the Chimney Tops II region. Models based on this external forecast would not be able to resolve the relevant interactions of topography with surface winds.

The simulations herein presented run in a few hours in a workstation. For example, using 14 Intel Xeon CPUs E5-2698 v3 at $2.30 \mathrm{GHz}$, the simulations run approximately at a five times faster pace than real time. Hence, they can be used by the fire management team in real time to assist them in the management of wildland fires. For example, SPOT1 and SPOT2 simulations would have finished at around 1500 LST and 1700 LST. Upon completion of these simulations, there would have been ample time to issue timely evacuation notice. Hence, the simulations could provide important and timely information to reduce impacts of wildland fires.

Author Contributions: P.A.J., D.M.-E. and B.K. designed research; P.A.J. performed research; and P.A.J., D.M.-E. and B.K. analyzed results and wrote the paper.

Acknowledgments: NCAR is sponsored by the National Science Foundation. We thank the CoE for providing us with the final fire perimeter of the Chimney Tops II fire. The HRRR analysis to create initial and boundary conditions for the WRF-Fire simulations are available at the University of Utah (https:/ / pando-rgw01.chpc.utah. edu/HRRR/oper/prs).

Conflicts of Interest: The authors declare no conflict of interest. The founding sponsors had no role in the design of the study; in the collection, analyses, or interpretation of data; in the writing of the manuscript, and in the decision to publish the results. 


\section{Abbreviations}

The following abbreviations are used in this manuscript:

$\begin{array}{ll}\text { NWP } & \text { numerical weather prediction } \\ \text { WRF } & \text { Weather Research and Forecasting } \\ \text { CAWFE } & \text { Coupled Atmosphere-Wildland Fire Environment } \\ \text { NCAR } & \text { National Center for Atmospheric Research } \\ \text { NOAA } & \text { National Oceanic \& Atmospheric Administration } \\ \text { CoE } & \text { Colorado Center of Excellence for Advanced Technology Aerial Firefighting } \\ \text { RMRS } & \text { Rocky Mountain Research Station } \\ \text { LST } & \text { Local Standard Time } \\ \text { SIM1 } & \text { First simulation } \\ \text { SIM2 } & \text { Second simulation } \\ \text { SIM3 } & \text { Third simulation } \\ \text { SPOT1 } & \text { First additional simulation } \\ \text { SPOT2 } & \text { Second additional simulation } \\ \text { HRRR } & \text { High Resolution Rapid Refresh }\end{array}$

\section{References}

1. Andrews, P.; Finney, M.; Fischetti, M. Predicting wildfires. Sci. Am. 2007, 297, 46-55.

2. Sullivan, A.L. Wiland surface fire spread modelling, 1990-2007. 1: Physical and quasi-physical models. Int. J. Wildland Fire 2009, 18, 349-368.

3. Sullivan, A.L. Wiland surface fire spread modelling, 1990-2007. 2: Empireical and quasi-empirical models. Int. J. Wildland Fire 2009, 18, 369-386.

4. Sullivan, A.L. Wiland surface fire spread modelling, 1990-2007. 3: Simulation and mathematical analogue models. Int. J. Wildland Fire 2009, 18, 387-403.

5. Finney, M.A.; Cohen, J.D.; Forthofer, J.M.; McAllister, S.S.; Gollner, M.J.; Gorhan, D.J.; Saito, K.; Akafuah, N.K.; Adam, B.A.; English, J.D. Role of buoyant flame dynamics in wildfire spread. Proc. Natl. Acad. Sci. USA 2015, 112, 9833-9838.

6. Cruz, M.G.; Alexander, M.E. Uncertainty associated with model predictions of surface and crown fire rates of spread. Envirion. Model. Softw. 2013, 47, 16-28.

7. Countryman, C.M. The Fire Environmnet Concept; Technical Report; USDA Forest Service, Pacific Southwest Forest and Range Experiment Station: Berkeley, CA, USA, 1972.

8. Clark, T.L.; Coen, J.L.; Latham, D. Description of a coupled atmosphere-fire model. Int. J. Wildland Fire 2004, 13, 49-63.

9. Mandel, J.; Beezley, J.D.; Kochanski, A.K. Coupled atmosphere-wildland fire modeling with WRF 3.3 and SFIRE 2011. Geosci. Model Dev. 2011, 4, 591-610.

10. Coen, J.L.; Cameron, M.; Michalakes, J.; Patton, E.G.; Riggan, P.J.; Yedinak, K.M. WRF-Fire: Coupled weather-wildland fire modeling with the Weather Research and Forecasting model. J. Appl. Meteor. Climatol. 2013, 52, 16-38.

11. Forthofer, J.M.; Butler, B.W.; Wagenbrenner, N.S. A comparison of three approaches for simulating fine-scale surface winds in support of wildland fire management. Part I. Model formulation and comparison against measurements. Int. J. Wildland Fire 2014, 23, 969-981.

12. Forthofer, J.M.; Butler, B.W.; McHugh, C.W.; Finney, M.A.; Bradshaw, L.S.; Stratton, R.D.; Shannon, K.S.; Wagenbrenner, N.S. A comparison of three approaches for simulating fine-scale surface winds in support of wildland fire management. Part II. An exploratory study of the effect os simulated winds on fire trowth simulations. Int. J. Wildland Fire 2014, 23, 982-994.

13. Benjamin, S.G.; Weygarndt, S.; Alexander, C.; Brown, J.M.; Smirnova, T.G.; Hofmann, P.; James, E.; DiMego, G. NOAA's hourly-updated 3 km HRRR and RUC/Rapid Refresh- Recent (2010) and upcoming changes toward improving weather guidance for air-traffic management. In Proceedings of the Second Aviation, Range and Aerospace Meteorology Special Symposium on Weather-Air Traffic Management Integration, Seattle, WA, USA, 22-27 January 2011. 
14. Skamarock, W.C.; Klemp, J.B.; Dudhia, J.; Gill, D.O.; Barker, D.M.; Duda, M.; Huang, X.Y.; Wang, W.; Powers, J.G. A Description of the Advanced Research WRF Version 3; Technical Report TN-475+STR; NCAR: Boulder, CO, USA, 2008.

15. Coen, J. Modeling Wildland Fires: A Description of the Coupled Atmosphere-Wildland Fire Environment Model (CAWFE); Technical Report, NCAR Technical Note NCAR/TN-500+STR; NCAR: Boulder, CO, USA, 2013.

16. Dudhia, J. Numerical study of convection observed during the winter monsoon experiment using a mesoscale two-dimensional model. J. Atmos. Sci. 1989, 46, 3077-3107.

17. Mlawer, E.J.; Taubman, S.J.; Brown, P.D.; Iacono, M.J.; Clough, S.A. Radiative transfer for inhomogeneous atmospheres: RRTM, a validated correlated-k model for the longwave. J. Geophys. Res. 1997, 102, 16663-16682.

18. Hong, S.Y.; Lim, J.O.J. The WRF single-moment 6-class microphysics scheme (WSM6). J. Korean Meteor. Soc. 2006, 42, 129-151.

19. Chen, F.; Dudhia, J. Coupling an advanced land surface hydrology model with the Penn State/NCAR MM5 modeling system. Part 1: Model description and implementation. Mon. Weather Rev. 2001, 129, 569-586.

20. Tewari, M.; Chen, F.; Wang, W.; dudhia, J.; LeMone, M.; Mitchell, K.; Ek, M.; Gayno, G.; Wegiel, J.; Cuenca, R. Implementation and verification of the unified NOAH land surface model in the WRF model. In Proceedings of the 84th AMS Annual Meeting (20th Conference on Weather Analysis and Forecating/16th Conference on Numerical Weather Predictio), Seattle, WA, USA, 14 Janurary 2004; pp. 11-15.

21. Jiménez, P.A.; Dudhia, J.; González-Rouco, J.F.; Navarro, J.; Montávez, J.P.; García-Bustamante, E. A revised scheme for the WRF surface layer formulation. Mon. Weather Rev. 2012, 140, 898-918.

22. Nakanishi, M.; Niino, H. Development of an improved turbulence closure model for the atmospheric boundary layer. J. Meteorol. Soc. Jpn. 2009, 87, 895-912.

23. Moeng, C.H.; Dudhia, J.; Klemp, J.B.; Sulivan, P.P. Examining two-way grid nesting for large eddy simulations of the PBL using the WRF model. Mon. Weather Rev. 2007, 135, 2295-2311.

24. Mirocha, J.; Lundquist, J.; Kosović, B. Implementation of a nonlinear subfilter turbulence stress model for large-eddy simulation in the Advanced Research WRF model. Mon. Weather Rev. 2010, 135, 2295-2311.

25. Rothermel, R.C. A Mathematical Model for Predicting Fire Spread in Wildland Fuels; Research Paper INT-115; USDA Forest Service: Ogden, UT, USA, 1972.

26. Muñoz-Esparza, D.; Kosović, B.; Jiménez, P.A.; Coen, J. An accurate fire-spread algorithm in the Weather Research and Forecasting model using the level-set method. J. Adv. Model. Earth Syst. 2018, 10, 908-926.

27. Albini, F.A. Program BURNUP: A Simulation of the Burning of Large Woody Natural Fuels; Final Report USDA Forest Service Research Grant INT-92754-GR; USFS to Montana State University Mechanical Engineering Department: Washington, DC, USA, 1972.

28. Albini, F.A. Calibration of a large fuel burnout model. Int. J. Wildland Fire 1995, 5, 173-192.

29. Albini, F.A. Estimating Wildfire Behavior and Effects; General Technical Report INT-30; USDA Forest Service: Ogden, UT, USA, 1976.

30. Anderson, H.E. Aids to Determining Fuel Models for Estimating Fire Behavior; General Technical Report INT-122; USDA Forest Service, Intermountaion Forest and Range Experiment Station: Ogden, UT, USA, 1982.

31. Perryman, H.A.; Dugaw, C.J.; Varner, J.M.; Johnson, D.L. A celluylar automata model to link surface fires to firebrand lift-off and dispersal. Int. J. Wildland Fire 2013, 22, 428-439.

32. Pagnini, G.; Mentrelli, A. Modelling wildland fire propagation by tracking random fronts. Nat. Hazards Earth Syst. Sci. 2014, 14, 2249-2263.

33. Tohidi, A.; Kaye, N.; Bridges, W. Statistical description of firebrand size and shape distribution from coniferous trees for use in Monte Carlo simulations of firebrand flight distance. Fire Saf. J. 2015, 77, 21-35.

34. Kaur, I.; Mentrelli, A.; Bosseur, F.; Filippi, J.B.; Pagnini, G. Turbulence and fire-spotting effects into wildland fire simulators. Commun. Nonlinear Sci. Numer. Simul. 2016, 39, 300-320.

35. Martin, J.; Hillen, T. The spotting distribution of wildfires. Appl. Sci. 2016, 6, 177.

36. Tohidi, A.; Kaye, N. Stochastic modeling of firebrand shower scenarios. Fire Saf. J. 2017, 91, 91-102. 
37. Fernandez-Pello, A.C. Wildland fire spot ignition by sparks and firebrands. Fire Saf. J. 2017, 91, 2-19.

38. Thomas, J.C.; Mueller, E.V.; Santamaria, S.; Gallagher, M.; Houssami, M.E.; Filkov, A.; Clark, K.; Skowronski, N.; Hadden, R.M.; Mell, W.; et al. Investigation of firebrand generation from an experimental fire: Development of a reliable data collection methodology. Fire Saf. J. 2017, 91, 864-871.

(C) 2018 by the authors. Licensee MDPI, Basel, Switzerland. This article is an open access article distributed under the terms and conditions of the Creative Commons Attribution (CC BY) license (http:/ / creativecommons.org/licenses/by/4.0/). 